This item was submitted to Loughborough's Research Repository by the author.

Items in Figshare are protected by copyright, with all rights reserved, unless otherwise indicated.

\title{
Hydrodynamic performance of vegetation surrogates in hydraulic studies: a comparative analysis of seaweed blades and their physical models
}

PLEASE CITE THE PUBLISHED VERSION

https://doi.org/10.1080/00221686.2018.1562999

\section{PUBLISHER}

Taylor \& Francis ( International Association for Hydro-Environment Engineering and Research

\section{VERSION}

AM (Accepted Manuscript)

\section{PUBLISHER STATEMENT}

This is an Accepted Manuscript of an article published by Taylor \& Francis in Journal of Hydraulic Research on 11 March 2019, available online: http://www.tandfonline.com/10.1080/00221686.2018.1562999.

\section{LICENCE}

CC BY-NC-ND 4.0

\section{REPOSITORY RECORD}

Vettori, Davide, and Vladimir Nikora. 2019. "Hydrodynamic Performance of Vegetation Surrogates in Hydraulic Studies: A Comparative Analysis of Seaweed Blades and Their Physical Models”. Loughborough University. https://hdl.handle.net/2134/36790. 
Hydrodynamic performance of vegetation surrogates in hydraulic studies: a comparative analysis of seaweed blades and their physical models DAVIDE VETTORI (IAHR Member), Postdoctoral Research Associate, Department of Geography, Loughborough University, Epinal Way, Loughborough LE11 3TU, UK.

Email:d.vettori@lboro.ac.uk (author for correspondence)

VLADIMIR NIKORA (IAHR Member), Professor, School of Engineering, University of Aberdeen, Aberdeen AB24 3UE, Scotland, UK.

Email:v.nikora@abdn.ac.uk

Running Head (i.e. the text that appears in the top margin of the published page):

Hydrodynamic performance of seaweeds and their surrogates 


\title{
Hydrodynamic performance of vegetation surrogates in hydraulic studies: a comparative analysis of seaweed blades and their physical models
}

\begin{abstract}
Vegetation surrogates have been extensively used in laboratory experiments for studying flow-vegetation interactions. However, it remains unclear how accurately the surrogates replicate the prototype vegetation in terms of hydrodynamic performance, even when similarity conditions are followed. To address this matter, we compare the hydrodynamic performance of seaweed blades of the species Saccharina latissima with performance of their surrogates, which were designed based on similarity considerations. To assess the hydrodynamic performance of samples, we measured flow velocities upstream and downstream of the samples, their vertical movements, and the drag forces exerted on them. The obtained data reveal that the mechanisms governing flow-blade interactions are essentially the same for live blades and their surrogates. Even though the surrogates successfully replicate many aspects of live blade dynamics, they experience weaker drag force and reconfiguration, likely because of their simplified morphologies that differed from the live blades at small scales. To enhance similarity in hydrodynamic performances, we suggest employing comprehensive similarity conditions at all relevant scales.
\end{abstract}

Keywords: Drag coefficient; flow-biota interactions; hydraulic models; similarity theory; turbulent wakes; velocity measurements

\section{Introduction}

Over the recent decades, aquatic vegetation has been extensively explored by hydraulic engineers and other aquatic researchers due to the important roles that aquatic plants play in stream ecology, sediment transport, and hydraulic resistance. The pioneering hydraulic studies involving in-stream vegetation were conducted by Kouwen, Unny, and Hill (1969) and Kouwen and Unny (1973) who examined the impact of vegetation on the roughness parameters used to estimate hydraulic conditions in open channels. Numerous studies on flow-vegetation interactions have followed, many of which made use of vegetation surrogates (e.g. Albayrak, Nikora, Miler, \& O’Hare, 2012; Folkard, 2005; Nepf, 2012; Okamoto, Nezu, \& Sanjou, 2016; Rominger \& Nepf, 2014; Siniscalchi, Nikora, \& Aberle, 2012; Wilson, Stoesser, Bates, \& Pinzen, 2003; Yang \& Choi, 2009), which allow a level of control over experimental conditions not achievable with live vegetation (Frostick, McLelland, \& Mercer, 2011; Thomas et al., 2014). Use of vegetation surrogates is particularly attractive in studies of flow-vegetation interactions at larger spatial scales (e.g. patch, canopy, reach scales) where many elements are required, while it is less common in studies at small spatial scales. For example, rigid cylinders have been used in a number of studies investigating flow within vegetated canopies (e.g. Ghisalberti \& Nepf, 2005; Lightbody \& Nepf, 2006), even though representing vegetation using rigid cylinders is not 
generally justifiable (Aberle \& Järvelä, 2013). Aquatic plants have also been reproduced using artificial rigid strips (Nezu \& Sanjou, 2008), artificial garden grass (Nikora, Nikora, \& O’Donoghue, 2013), and strips prepared from polyethylene sheeting (Folkard, 2005). At a smaller scale, Albayrak et al. (2012) studied the effects of mechanical properties and morphological characteristics of leaves on flow-vegetation interactions. While in a few studies surrogate design was based on similarity considerations for geometric properties and mechanical characteristics (e.g. Folkard, 2005), most research up-to-date has been conducted using vegetation surrogates selected either intuitively or based on their availability rather than guided by a rigorous similarity theory (e.g. Albayrak et al., 2012; Nikora et al., 2013; Okamoto et al., 2016; Siniscalchi et al., 2012).

In recent years, the development of multiple potential applications of seaweeds (see Lucas \& Southgate, 2012 for details on applications) has motivated growing studies of the interactions between flow and seaweeds, particularly in relation to the optimal design of seaweed farms. Surrogates of seaweeds (or seaweed blades) have been employed by Johnson (2001) and Stewart (2006), who did not consider similarity theory when scaling their samples, and by Rominger and Nepf (2014), Fryer et al. (2015) and Vettori and Nikora (2018), who designed and manufactured their surrogates according to a similarity theory that accounts for most significant parameters in play. These studies have contributed to better understanding of how seaweeds interact with the flow at a range of hydraulic conditions and for a variety of morphological and mechanical characteristics of the surrogates. To our knowledge, however, the performance of seaweed surrogates has never been assessed in terms of how well they reproduce the dynamics of their prototypes. The same actually applies to the whole area of flow-vegetation interactions where the level of comprehensiveness with which vegetation surrogates should be designed remains unknown.

Whilst in conventional hydraulic applications we mainly deal with static structures, in studies of flow-vegetation interactions we must account for vegetation reconfiguration where relevant. In situations where vegetation does not deform or move, maintaining conventional geometric and dynamic similarity (e.g. plant Reynolds number) may be sufficient. However, such cases are fairly rare and most aquatic and riparian plants experience reconfiguration at a broad range of hydraulic conditions. Furthermore, the overall reconfiguration should be considered as a combination of posture (i.e. static reconfiguration) and motion (i.e. dynamic reconfiguration, sensu Siniscalchi \& Nikora, 2013), as these two distinct forms of reconfiguration may affect plant performance differently. Therefore, an ideal replica would not only fully satisfy the geometric similarity, but also broader kinematic and dynamic similarities, including those related to material properties. Unfortunately, preserving all three similarity types in a surrogate design is often difficult, particularly when a surrogate is down-scaled. Nevertheless, design of vegetation surrogates should follow a similarity framework as closely as possible, by taking into 
account the most important governing parameters in the prototype (e.g. de Langre, 2008; Nikora, 2010; Thomas et al., 2014). To support this approach, the current knowledge of morphological and mechanical characteristics of aquatic vegetation needs to be expanded.

Even though the use of similarity considerations in flow-vegetation interaction studies appears to be spreading in the hydraulic community, it is still unclear what degree of comprehensiveness is required in the design of a surrogate for it to replicate the hydrodynamic performance of the prototype organism sufficiently. For example, Aberle and Järvelä (2013) and Boothroyd, Hardy, Warburton, and Marjoribanks (2016) concluded that the presence of leaves in riparian vegetation has a considerable impact on both the drag force experienced by vegetation and the way in which it modifies the flow characteristics. At a leaf scale, Albayrak et al. (2012) reported that roughness, shape, and serration (and their combination) can alter considerably the drag force exerted by a turbulent flow on a leaf replica. Since the hydrodynamic performance of any organism depends on the elements of which it is composed, it is useful to start an investigation of vegetation hydrodynamics from the simplest element, i.e. a leaf or a blade.

In the present paper we compare the performance of seaweed blades of the species Saccharina latissima with the performance of their plastic surrogates designed using major geometrical and mechanical characteristics, but without taking into account minor morphological features. $S$. latissima was chosen because of its relatively simple morphology and its potential employment in seaweed farming (Vettori, 2016). Blade surrogates were designed and manufactured according to a similarity framework proposed in Vettori and Nikora (2018). Hydrodynamic performance of individual test samples at a range of hydraulic conditions was assessed in a laboratory flume by measuring flow velocities upstream and downstream from the samples, instantaneous drag force exerted by the flow on the samples, and their vertical position and movements (i.e. static and dynamic reconfiguration). The interrelations between flow turbulence, fluctuations of the drag force and sample reconfiguration are also examined to shed a light on the mechanisms controlling samples hydrodynamics. Ultimately, we seek to evaluate if the surrogates we designed and manufactured are appropriate replicas of live seaweed blades. In addition, we aim to understand what degree of comprehensiveness for the design of vegetation surrogates is required. In this paper we use extensive data sets previously reported in Vettori (2016) and Vettori and Nikora (2018) to characterize the hydrodynamics of seaweed blades and their surrogates, respectively. Section 2 contains a description of the test samples (i.e. seaweed blades and their surrogates), instrumentation, and data processing techniques used in this study. In Section 2 we also compare the morphology and the mechanical properties of test samples. In Section 3 results and findings of the study are reported focusing on the drag forces acting on the test samples, their reconfiguration, sample effects on the downstream flow characteristics, the speed of propagation of oscillations along the samples, and the location of the resultant drag force action within a sample. In Section 4 we discuss the results of the study and provide an 
assessment of how well our seaweed blade surrogates replicate the performance of live seaweed blades.

\section{Materials and methods}

\subsection{Test samples}

Surrogates of blades of S. latissima were designed based on a similarity theory for seaweed blades proposed in Vettori and Nikora (2018). For typical experimental conditions, it allows achieving approximate geometrical, kinematic, and dynamic similarities by keeping the blade Reynolds number $\left(\mathrm{R}_{\mathrm{l}}=U_{u p} l / v\right.$, where $U_{u p}$ is the mean upstream longitudinal velocity, $l$ is the length of test sample, and $v$ is water kinematic viscosity) and the Cauchy number $\left(\mathrm{C}_{\mathrm{y}}=\right.$ $\rho U_{u p}{ }^{2} l^{3} /\left(E_{s} t^{3}\right)$, where $\rho$ is water density, $E_{s}$ is the bending Young's modulus of test sample, and $t$ is the thickness of test sample) identical for both the prototypes and the surrogates. In the design of blade surrogates, we used published data on morphological characteristics and mechanical properties of seaweed blades (Buck \& Buchholz, 2005; Boller \& Carrington, 2007; Spurkland \& Iken, 2012). Since the available studies report only mean values for the blade width $b$ and thickness $t$, surrogates were manufactured with constant width and thickness although the blade ends were made rounded to replicate a natural shape (Fig. 1). It is also noted that Boller and Carrington (2007) report an estimate of S. latissima Young's modulus at tension rather than bending; nevertheless, their estimate was used as a reference due to the lack of alternative information. Nine surrogates with a range of morphological characteristics and mechanical properties were manufactured using low density polyethylene sheeting and tested in 2014, prior to examining live seaweed blades. The scale ratios obtained from similarity considerations were 1:5 for geometrical parameters, 1:1 for mass density, and 25:1 for Young's modulus. Due to technical and material limitations these target scale ratios were kept only approximately. A summary of surrogates' characteristics is provided in Table 1. A full account of the similarity considerations for seaweed blades and the design and manufacture of the surrogates is given in Vettori and Nikora (2018). Each surrogate blade was tested at seven flow scenarios described in Table 2 .

About 80 samples of S. latissima were collected on the $10^{\text {th }}$ of February 2015 from long lines deployed at a seaweed farm in Loch Fyne (Scotland, coordinates of the site: $56.08 \mathrm{~N}$ and 5.28 W, for further details see Vettori \& Nikora, 2017). Seaweed samples were kept in seawater during transportation to the University of Aberdeen. Within 12 hours from collection the samples were placed in a 1251 outdoor tank filled with seawater and featuring a custom-made aeration system. Samples collected were sorted into five groups depending on the length of their blade (Vettori, 2016); from each group three blades as similar as possible in length and width were selected and used in flume experiments (Table 1). Since flume experiments were 
conducted in freshwater, which can induce changes in seaweed mechanical properties (Vettori, 2016; Vettori \& Nikora, unpublished), each blade was tested at a single flow scenario only and subsequently discarded. For each group, a separate blade was tested at flow scenarios 'Run1', 'Run 4', and 'Run 7', respectively (Table 2). Only these three flow scenarios were used for live seaweed blades due to time and seaweed supply limitations. Flume experiments with seaweed blades were conducted within 14 days from samples' collection. Just before a test in the flume, seaweed holdfasts and most of its stipe were removed (a part of the stipe was maintained to attach the blade to the Drag Measurement Device, see 2.2 Experimental set-up below) so the blade alone was tested. Only blades with no clear signs of deterioration (e.g. flaws, tears, fissures) were used in the flume experiments.

Morphologies of seaweed blades and surrogates are compared qualitatively and quantitatively in Fig. 1 by superimposing the contour of a surrogate with a photo of a live blade and displaying the wetted area of test samples as a function of their length, respectively. From Fig. 1 it is evident that both the shape and the surface area of surrogates differ, to some degree, from those of live blades used in the flume experiments. As discussed in Vettori and Nikora (2017), this variation appears to be due to the different environmental (e.g. hydraulic) conditions to which seaweeds had been exposed and adapted. Seaweed samples studied by Buck and Buchholz (2005), which were used as prototypes for our surrogates, were collected from exposed site, while live blades considered in the present study were collected from a relatively sheltered site (Vettori \& Nikora, 2017).

\subsection{Experimental set-up}

The hydrodynamic performance of test samples was evaluated by conducting experiments in a $12.5 \mathrm{~m}$ long, $0.3 \mathrm{~m}$ wide, and $0.45 \mathrm{~m}$ deep tilting recirculating flume in the Fluid Mechanics Laboratory of the University of Aberdeen (Scotland, UK). Experiments were carried out at quasi-uniform flow conditions with a water depth $\left(H_{w}\right)$ set to $0.3 \mathrm{~m}$. The test samples were located in the flume central section $0.22 \mathrm{~m}$ above the flume bed to minimize the effects of the flume boundaries. The drag force experienced by a test sample was measured at $200 \mathrm{~Hz}$ using a Drag Measurement Device (DMD), which included a load cell featuring a Wheatstone bridge (the instrument design is described in Vettori and Nikora, 2018). The flow velocities upstream and downstream of a test sample were measured at $100 \mathrm{~Hz}$ using two Vectrino + (Nortek AS, Rud, Norway) Acoustic Doppler Velocimeters (ADVs) whose sampling volumes were located at the same height of the test sample and $0.2 \mathrm{~m}$ upstream of its clamped end and $0.1 \mathrm{~m}$ downstream of its free end, respectively. Test sample reconfiguration was assessed by analysing videos recorded with a Full HD digital camera (HD HMX-R10BP, Samsung, Seoul, South Korea, resolution of 1920x1080 pixels) at $25 \mathrm{~Hz}$. The camera was located on the side of a flume glass wall so that the recorded video provided a complete side-view of the test sample at all times 
during an experiment. An overview of the experimental setup is displayed in Fig. 2.

Synchronisation of the ADVs and the DMD was achieved in every experiment via a voltage output trigger. Videos of live seaweed blades were synchronized with ADVs and DMD during video post-processing.

Experiments with blade surrogates had a duration of 10 minutes; a comprehensive description of the experimental setup can be found in Vettori and Nikora (2018). Experiments with live seaweed blades lasted for about 80 minutes; however, we focus our analysis on the last 10minute window. This was done because the drag force experienced by seaweed blades decreased considerably for the first 30-50 minutes of experiments (Vettori, 2016; Vettori \& Nikora, unpublished). Such a decrease is likely to be caused by two factors: (i) increase in seaweed material flexibility because of freshwater exposure (Vettori \& Nikora, unpublished); and (ii) adjustment of the blade response to the experimental hydraulic conditions which differed from those where samples were collected. Since we could not quantify the change in elastic Young's modulus $E_{s}$ associated with the exposure to experimental conditions, the value of $E_{s}$ reported in Table 1 refers to seaweed material before exposing to flowing freshwater in the flume. The last 10-minutes window in the total records was chosen for consistency with experiments with blade surrogates and because live blades appeared to have completed their adaptation to the experimental conditions. Thus, the measured signals are considered to be (quasi)stationary in a statistical sense.

\subsection{Data processing and analysis}

Data of drag force were filtered with an anti-aliasing low-pass FIR filter during conversion from analogue to digital signal. This introduced a delay of $0.025 \mathrm{~s}$ in the data that is assumed to be negligible for further analysis. Due to the high sensitivity of the load cells used in the DMD, mechanical micro-vibrations inherent to the facility and DMD structure contaminated the measured drag force signal at frequencies higher than $5 \mathrm{~Hz}$. For live seaweed blades the statistical moments of the drag force are not affected noticeably by these micro-vibrations, although the drag spectra $S_{d}$ do exhibit some narrow peaks at frequencies higher than $5 \mathrm{~Hz}$ (Fig. $4 a)$. Note that these peaks were not removed during data processing to preserve $S_{d}$ original shape and characteristics. On the other hand, the drag force signal of blade surrogates was processed with an additional low-pass FIR filter (cut-off frequency set to $4.5 \mathrm{~Hz}$ ) to cut off the frequencies affected by external vibrations. This second filtering was required because the drag variance $\sigma_{d}^{2}$ would have been significantly biased otherwise by the contributions from micro-vibrations (Fig. 4a). The filtered signal was then used to calculate all relevant statistical quantities for drag force. Since samples were streamlined, with a deflected height of an order of magnitude smaller than the sample length $l$, the main contribution to the total drag is from the viscous drag. Therefore, we used the wetted blade area $A_{\text {wet }}$ as a reference area and thus the drag coefficient was 
calculated as $\mathrm{C}_{\mathrm{d}}=F_{\mathrm{d}} /\left(0.5 \rho A_{\text {wet }} U_{u p}{ }^{2}\right)$, where $F_{d}$ denotes the time averaged drag force. Velocity data collected with the ADVs were despiked using the modified phase-space threshold method, with removed points replaced using the last good value approach (Goring \& Nikora, 2002; Parsheh et al., 2010).

Vertical positions of a test sample during experiments were extracted from videos using the Canny edge detector algorithm (Canny, 1986). Vertical positions were obtained for a number of cross-sections along the test sample, but here we focus our analysis mainly on the free end of the test sample, as this position is the most representative for the whole sample (Vettori \& Nikora, 2018). From the signal of blade vertical position $z_{b}$ thus obtained, the vertical velocity $w_{b}$ of a blade was estimated as a time derivative of $z_{b}$. Applying a cross-correlation technique to the vertical positions of two cross-sections along a test sample, we also estimated the propagation velocity $V_{p}$ of oscillations of blades (full description is given in Vettori, 2016). The time delay associated with the maximum value of the cross-correlation between the vertical position $z_{b}$ of two cross-sections was interpreted as the time period required for a perturbation to move from the upstream location to the downstream location. The propagation velocity $V_{p}$ was then estimated as the ratio of the distance between the selected cross-sections to the travel time thus obtained.

Further, we also estimated the location of the resultant drag force following the same method as proposed in Siniscalchi and Nikora (2012). This parameter can provide additional information on the mechanisms adopted by a blade to control drag. The method is based on cross-correlation functions between the flow longitudinal velocities upstream $u_{u \mathrm{p}}$ and downstream $u_{d s}$ of a test sample and the drag force $d$ experienced by the sample. By identifying the maximum in the cross-correlation function between $d$ and either $u_{u \mathrm{p}}$ or $u_{d s}$, the time delay $\Delta \tau$ between the two signals was estimated. Using $\Delta \tau$ and the bulk convection velocity $U_{c}$, which can be assumed to be equal to the mean approach velocity in front of a test sample $U_{u p}$ in the cases investigated (as Taylor's hypothesis of frozen turbulence was found to be valid, Vettori 2016), the distances between two signal sources (Fig. 2) were estimated, i.e.:

$$
\begin{aligned}
& L_{u p}=U_{c} \Delta \tau_{u-d} \\
& L_{d s}=U_{c} \Delta \tau_{u-d}
\end{aligned}
$$

where $L_{u p}$ and $L_{d s}$ are the distances between the sources of the signals $u_{u \mathrm{p}}$ and $d$, and $d$ and $u_{d s}$, respectively, and $\Delta \tau_{u-d}$ and $\Delta \tau_{d-u}$ are the time delays between $u_{u \text { p }}$ and $d$, and $d$ and $u_{d s}$, respectively. Employing these parameters, it is possible to assess the validity of this approach by comparing the distance between two ADVs with the sum of $L_{u p}$ and $L_{d s}$. The distance of the location of the resultant drag force from the clamped sample end $D_{\text {res }}$ is estimated as the difference between $L_{u p}$ and the distance between the upstream ADV and the part of the DMD 
holding the test sample (i.e. $0.2 \mathrm{~m}$ ) (Fig. 2).

\section{Results}

Since seaweed blades and surrogates are characterized by different sizes, to conduct a valid comparison of their hydrodynamic performance we make use of normalized parameters and functions such as the drag coefficient $\mathrm{C}_{\mathrm{d}}=F_{\mathrm{d}} /\left(0.5 \rho A_{\text {wet }} U_{u p}{ }^{2}\right)$, normalized power spectra $S(\mathrm{f})$ (i.e. $S / \sigma^{2}$, where $\sigma^{2}$ is signal variance), coherence functions (e.g. $\gamma^{2}{ }_{u-d}=\left|S_{u-d}\right|^{2} /\left(S_{u} S_{d}\right)$, where $\left|S_{u-d}\right|$ is the module of the cross-spectrum between two signals, and $S_{u}$ and $S_{d}$ are auto-spectra of upstream longitudinal velocity and drag signals, respectively) and squared gain factors (e.g. $\left|H_{w b-w}\right|^{2}=$ $S_{w b} / S_{w-u p}$, where $S_{w b}$ and $S_{w-u p}$ are auto-spectra of sample vertical velocity and upstream vertical velocity, respectively). The coherence function can be viewed as a frequency-dependent squared correlation coefficient between $u_{u p}$ and $d$. The squared gain factor describes how fluctuations of a signal (e.g. $w_{b}$ ) are dependent on the corresponding fluctuations of another signal (e.g. $w_{u p}$ ) at a particular frequency.

\subsection{Dragforce}

A non-dimensional parameter often used to assess the efficiency of reconfiguration mechanisms in keeping the mean drag force $F_{d}$ low when the mean flow velocity increases is known as Vogel's exponent $E$. Its expression was first introduced by Vogel (1994) as a parameter in the relation $F_{d} \propto U_{u p}{ }^{2+E}$. If values of $E$ at high $\mathrm{R}_{\mathrm{l}}$ are negative then the mean drag force at a particular approach velocity is less compared to that for a rigid object of the same shape. The ranges of the obtained values of $E$ for seaweed blades and their surrogates are similar, varying from -0.6 to -0.2 and from -0.6 to 0.2 , respectively. Most surrogates are characterized by negative Vogel's exponent, with exceptions of two long samples (i.e. 'L8', 'L9'). The drag coefficient of surrogates is typically biased low compared to that of the seaweed blades used in the experiments (Fig. 3). While for $\mathrm{R}_{\mathrm{l}}$ lower than $2 \times 10^{4}$ the difference between them is negligible, the surrogates' $C_{d}$ is approximately $50 \%$ lower than that of seaweed blades for higher values of $R_{l}$ (Fig. 3a). The divergence of the drag coefficients is more pronounced when considering their dependence on the Cauchy number $\mathrm{C}_{\mathrm{y}}$ (Fig. 3b) where, partially due to deviations of $E_{s}$ and $t$ from target values followed from similarity consideration, $\mathrm{C}_{\mathrm{d}}$ values of the surrogates exhibit no overlap with the range of $C_{d}$ for seaweed blades. Values of $C_{d}$ of the surrogates at particular $\mathrm{C}_{\mathrm{y}}$ are from three to five times lower than those of seaweed blades. This considerable difference is likely to be related to the morphological differences between the surrogates and live blades.

Fluctuations of the drag force are assessed using the spectrum of drag $S_{d}$ normalized by the drag variance $\sigma_{d}^{2}$ (Fig. 4a) and the coherence function $\gamma^{2}{ }_{u-d}$ between the longitudinal flow velocity 
upstream of the sample and the drag force (Fig. 4b). The similarity in the spectra of the drag force is evident up to $4.5 \mathrm{~Hz}$, at which frequency the spectra for surrogates are cut off. For all cases one can note a '-1' scaling region at frequencies lower than about $0.1-0.2 \mathrm{~Hz}$ and a ' $-5 / 2$ ' scaling region between $0.1-0.2 \mathrm{~Hz}$ and $5-10 \mathrm{~Hz}$ (Fig. 4a). Exceptions from this behaviour relate to the surrogates ' $\mathrm{L} 1$ ' and ' $\mathrm{L} 2$ ', whose spectra have a single scaling region where spectra decay following a '-1' power law. This peculiarity is discussed in Vettori and Nikora (2018), where we suggest it be associated with the fact that for surrogates 'L1' and 'L2' at low-flow scenarios the ratio of sample length to integral turbulence length scale is less than 1 . This condition may limit sample's ability to 'dampen' medium-high frequency drag fluctuations, because the sample cannot be compliant with the dominant eddies. The coherence functions $\gamma_{u-d}^{2}$ are almost identical for seaweed blades and surrogates (Fig. 4b), attaining maximum values at $f l / U_{u p}<0.2$ and losing its statistical significance at around $f l / U_{u p}=0.5-1$. This indicates that eddies much larger than the sample length are very efficient in inducing drag fluctuations, while eddies with length scale lower than sample length do not generate noticeable drag fluctuations.

\subsection{Reconfiguration}

The bulk statistics of vertical position and velocity of surrogates are in general agreement with those of seaweed blades. For example, the mean vertical position is almost constant along the test samples (i.e. samples are streamlined with the main flow) and the mean vertical velocity is zero. In both cases, the standard deviation $\sigma_{z b}$ of the vertical position $z_{b}$ increases quasi-linearly along the samples. The main difference between surrogates and live seaweed blades lies in the magnitude of $\sigma_{z b}$, which is one order of magnitude higher for seaweed blades even when comparing test samples of similar length. As shown in Fig. 5a where sample vertical velocity time series for a live blade and a surrogate of comparable length are displayed, live blades are characterized by fluctuations in vertical velocity $w_{b}$ that are considerably amplified compared to those of surrogates. For more detailed statistical analysis of both seaweed blades and their surrogates we further focus on the free end of the blades which is considered as a representative descriptor of the whole blades (Vettori, 2016; Vettori \& Nikora, 2018).

Figure $5 \mathrm{~b}$ shows the spectra $S_{w b}$ of the vertical velocity of test samples (i.e. their free end), normalized by $\sigma_{w b}^{2}$ and expressed as a function of the ratio $f l / U_{u p}$ of the sample length $l$ to the eddy wavelength $U_{u p} f$. For both seaweed blades and surrogates plots of $S_{w b} / \sigma^{2}{ }_{w b}$ show the same patterns, with the spectra collapsing within the same family of curves (Fig. 5b). Therefore, the spectral dynamics of the test samples appear to be similar regardless of the nature of the samples. However, for live seaweed blades the normalized spectra have a wider peak region (i.e. more broadbanded), suggesting that the dynamics of live seaweed blades is characterized by movements with a range of wavelengths broader than that of surrogates. 
Analysis of the squared gain factor $\left(\left|H_{w b-w}\right|^{2}=S_{w b} / S_{w-u p}\right)$ of the upstream vertical velocity and test sample vertical velocity (Fig. 5c) provides further indication on the dynamics of test samples. Considering the general trends, live seaweed blades and their surrogates perform similarly, but two differences are noticeable: (1) neglecting the peaks at high frequencies that are associated with the effect of vortex shedding on sample's free end (Vettori \& Nikora, 2018), $\left|H_{w b-w}\right|^{2}$ have a fairly narrow peak at $f l / U_{u p}=0.3-2$ for surrogates, while the region of maximum values for seaweed blades is broader, manifesting from 0.2 to 10 ; and (2) the magnitude of $\left|H_{w b-w}\right|^{2}$ for surrogates is considerably higher than that for the seaweed blades at most frequencies. These results indicate that: (i) the turbulent structures that drive motions of test samples (regardless of their nature) most efficiently are those with wavelengths comparable to $l$; and (ii) surrogates mainly interact with turbulent structures with wavelengths between $0.5 l$ and $3 l$ (i.e. $f l / U_{u p}$ from 0.3 to 2 ) while seaweed blades interact with a broader range of turbulent structures between $0.1 l$ and $5 l$ in size.

\subsection{Effects on flow characteristics}

Both seaweed blades and surrogates were found to reduce the mean flow velocity and enhance turbulence in the wake region behind them (Vettori, 2016; Vettori \& Nikora, 2018, unpublished). A vortex shedding phenomenon was identified downstream of both seaweed blades and surrogates at low mean flow velocities (i.e. flow scenarios 'Run 1', 'Run 2' and 'Run 3').

Among flow velocity components, the longitudinal component $u$ is the most affected by test samples followed by $w$, while $v$ appears to be essentially unaltered. Using the squared gain factors $\left(\left|H_{u-u}\right|^{2}=S_{u-d s} / S_{u-u p}\right.$ and $\left.\left|H_{w-w}\right|^{2}=S_{w-d s} / S_{w-u p}\right)$ of flow velocities upstream and downstream of test samples (Fig. 6) we can compare the wavelengths of the turbulent structures affected by the samples. It is apparent that live seaweed blades have a more considerable effect on longitudinal velocity than surrogates, while the magnitude of $\left|H_{w-w}\right|^{2}$ for vertical velocity is roughly the same for live blades and surrogates. Seaweed blades enhance fluctuations of the streamwise velocity $u$ by up to 10 times from $f l / U_{u p}=5$ to 30 (Fig. 6 a) or in absolute values between approximately $0.01 \mathrm{~m}$ and $0.1 \mathrm{~m}$ (Fig. 6b). Surrogates enhance turbulence in a very narrow band with wavelengths smaller than $0.05 \mathrm{~m}$ (Fig. 6b). The effects of test samples on the fluctuations of the vertical velocity $w$ are similar when analysed as a function of the ratio $f l / U_{u p}$ of the sample length to the eddy wavelength (Fig. 6c), but show a relative divergence when analysed as a function of the wavelength (Fig. 6d). Both types of test samples increase fluctuations of $w$ by up to 5 times at a range of lengths between $0.03 l$ and $0.2 l$ (Fig. 6c). In absolute values, the scale ranges characterized by turbulence enhancement for $w$ coincide with those for $u$ (Figs $6 \mathrm{~b}$ and $6 \mathrm{~d}$ ). 


\subsection{Propagation of sample oscillations}

The propagation velocity $V_{p}$ of oscillations on test samples is normalized using the mean flow velocity in Fig. 7a, where it is shown as a function of the blade Reynolds number. Regardless of the nature of the test samples, $V_{p} / U_{u p}$ has maximum values at low $\mathrm{R}_{\mathrm{l}}$ and tends to unity as $\mathrm{R}_{\mathrm{I}}$ increases (Fig. 7a). It is possible that this effect can be explained by noting that the variation of the blade Reynolds number is mainly due to the varying blade length. Thus, the ratios of the prevailing turbulence scale and the wavelength of the prevailing mode of blade vibration (that depends on the blade shape and elasticity) to the blade length sharply increases with decrease in $\mathrm{R}_{\mathrm{l}}$, making motions of short blades similar to those of quasi-rigid bodies. This will lead to sharply reduced time shifts of cross-correlation maximums between any two locations on the blades and consequently to increased values of $V_{p}$.

The magnitude of the propagation velocity is slightly different for surrogates and seaweed blades, with $V_{p} / U_{u p}$ being lower for surrogates. This deviation might be caused, to a certain degree, by the procedures applied in the video analysis. For surrogates, blade vertical position $z_{b}$ within a cross-section - which was set to be 10 pixels wide - was estimated as the mean of the vertical coordinates of all sample edges detected in that cross-section (Vettori \& Nikora, 2018). For live seaweeds, blade vertical position $z_{b}$ within a cross-section - 10 pixels wide - was estimated as the centre between the upper and lower sample contours in that cross-section. This simpler procedure was used for live seaweeds because the algorithm detected as edges also some macro-features in the central part of a blade (e.g. bullations) that would have affected the estimate of blade vertical position. Since live seaweeds are considerably wider than surrogates and with ruffled edges, not using the lower and upper edges of the blade to estimate the vertical velocity $w_{b}$ can potentially lead to its underestimation. Interestingly, considering dependences on the blade Reynolds number the trends shown by $V_{p} / U_{u p}$ are somewhat similar to those of the drag coefficient (Fig. 3a).

\subsection{Location of the resultant drag force}

The location of the resultant drag force differs considerably between seaweed blades and their surrogates (Fig. 7b). Live seaweed blades are characterized by a $D_{\text {res }}$ ranging from $0.4 l$ to $0.6 l$ an evidence of a (quasi)uniform contribution to drag force over blades. However, the surrogates display a $D_{\text {res }}$ located closer to the clamped end of the sample, between $0.05 \mathrm{l}$ and $0.25 \mathrm{l}$ in most cases, but with some outliers exceeding $0.3 l$ or equal to 0 . This suggests that the upstream part of the surrogates has a major contribution to the overall drag force, while the contribution of the downstream part close to the free end is insignificant. In addition, the resultant drag force for all test samples appear to move downstream as the mean flow velocity increases (Fig. 7b) not being affected by the length of test samples. The accuracy of the estimation of $D_{\text {res }}$ was assessed by 
comparing the distance between the ADVs with the sum $\left(L_{u p}+L_{d s}\right)$ (Fig. 2, Vettori 2016). The estimated differences are below $10 \%$ in $90 \%$ of the cases investigated and never above $30 \%$; moreover, the outliers visible in Fig. $7 \mathrm{~b}$ are never associated with errors above 10\%.

\section{Discussion}

Results of the present study show that $C_{d}$ of surrogates is biased low compared to that of live seaweed blades, with a $50 \%$ difference when considering $C_{d} v s R_{l}$ and a more marked difference in the plots of $\mathrm{C}_{\mathrm{d}} v s \mathrm{C}_{\mathrm{y}}$. The revealed deviations can be attributed to the different morphologies of surrogates and seaweed blades which are apparent in Fig. 1 both in terms of sample's shape and wetted surface area. Live seaweed blades are wider towards the stipe and more streamlined (i.e. narrower) towards the distal end, while surrogates have a constant cross-section (except for their rounded ends). Further, live blades display roughness elements such as ruffled edges and bullations on their central fascia that are not reproduced on surrogates. These features of live seaweed blades are expected to magnify the drag force live blades experience compared to that felt by surrogates. The variation of morphological characteristics encountered in this study is associated with the ability of seaweeds to adapt to the environmental conditions to which they are exposed. This ability is referred to as phenotypic plasticity and is a fundamental property of vegetation (e.g. Schlichting, 1986). We designed our surrogates using the data available in the literature (i.e. Buck \& Buchholz, 2005; Spurkland \& Iken, 2012) that referred to seaweeds grown at exposed sites. Conversely, live seaweed samples used in our study were collected from a sheltered location (Vettori \& Nikora, 2017). In terms of mechanical properties, the mass density $\rho_{s}$ of surrogates is similar to that of seaweed blades (as per target value), but their Young's modulus at bending $E_{s}$ is usually higher than the target value obtained from the 25:1 scale ratio (Table 1). These deviations, however, should not impact the results significantly, as the surrogates with $E_{s}$ closer to the target value do not perform more consistently with seaweed blades than other surrogates. Our results, therefore, indicate that $C_{y}$ as defined in Section 2.1 is not a sufficient non-dimensional parameter for describing the hydrodynamic performance of seaweed blades. In order to be used for vegetation with relatively complex morphologies, $\mathrm{C}_{\mathrm{y}}$ should be either modified to incorporate additional information (e.g. the roughness of a blade) or applied individually to different parts of an organism (e.g. stems, leaves/blades).

The influence of sample morphology is also apparent in the analyses of test sample dynamics and of the effects of test sample on the flow characteristics. The dynamics of the surrogates are controlled by the turbulent structures within a narrow range of spatial scales, while the dynamics of seaweed blades are affected by a wider range of eddies. Test sample dynamics is examined in Fig. 5 focusing on the vertical velocity of test sample's free end. Reconfiguration of test samples is expressed in the form of oscillations with a range of normalized wavelengths $f l / U_{u p}=0.2-10$ for seaweed blades and $f l / U_{u p}=0.3-2$ for the surrogates (Fig. $5 \mathrm{~b}$ ). Similar ranges of spatial 
scales are obtained for the turbulent structures that drive sample dynamics most efficiently (Fig. $5 \mathrm{c}$ ). We also note that the peaks present at high frequencies in Fig. $5 \mathrm{c}$ are generated by vortices shed by test sample's free end at low flow velocities. These vortices can feed test sample dynamics by inducing 'vibrations' within a well-defined frequency range. These vibrations are referred to as vortex-induced vibrations in the study of flow-structure interactions and are selfpowered, meaning that the same vibrations of the free end induced by the aforementioned vortices contribute to generating vortices in the wake (for a comprehensive description of this phenomenon, see Naudascher \& Rockwell, 2005). Further, the effects of the test samples on fluctuations of the streamwise velocity $u$ in the sample wake are enhanced considerably in the case of seaweed blades, both in terms of magnitude and range of spatial scales. This is not related to the size of the samples, as surrogates were as long as seaweed blades (or with compatible wetted surface area) in a number of cases, but appears to be due to the complex morphological nature of seaweed blades (with ruffled edges and bullations) that causes more variability in sample vertical position $z_{b}$ and velocity $w_{b}$.

Even though the surrogates do not fully replicate wide-ranging interactions with the flow of live seaweed blades, they still successfully simulate many aspects of the seaweed blade hydrodynamics. First, the trend of $C_{d}$ in the plot $C_{d} v s R_{l}$ is the same for seaweed blades and their surrogates, similar to that of a flat plate parallel to the flow (Vettori \& Nikora, 2018). Second, the efficiency with which fluctuations in $u_{u p}$ generate fluctuations in $d$ is essentially the same for live seaweed blades and their surrogates (Fig. 4b). Third, spectral analysis of the drag force and vertical velocity of a sample show a number of similarities between seaweed blades and their surrogates: (i) for both types of samples $S_{d}$ is well described by two characteristic scaling regions (i.e. with slopes -1 and $-5 / 2$ at a log-log scales), reflecting passive and active interactions between a sample and the flow (Fig. 4a, Vettori \& Nikora, 2018); (ii) their $S_{w b}$ are very similar, with most sample reconfiguration associated with oscillations with wavelengths comparable to the sample length $l$; and (iii) turbulent structures with wavelengths similar to $l$ are the most efficient in driving sample reconfiguration for both types of samples (Fig. 5c). Fourth, the effects of test samples on the fluctuations of the vertical velocity $w$ downstream of a sample are nearly independent of the nature of the sample (Fig. 6c-d), while the normalized propagation velocity of oscillations $V_{p} / U_{u p}$ shows common characteristics for seaweed blades and their surrogates (Fig. 7a). The estimated resultant drag force is located at the centre of a sample for live seaweed blades, while it is close to the clamped end for the surrogates. The character of this difference is unexpected, as the stretched droplet shape of live blades (Vettori \& Nikora, 2017) would suggest that the upstream part of a blade is the main contributor to the overall drag force. Thus, the natural evolution of seaweed blades appears to grant them a more 'balanced' design compared to that of our surrogates. The reasons for this difference and potential consequences on seaweed survival strategy are not clear yet. 
The results of this study evince that accounting for morphological macro-features such as bullations, ruffles and overall shape is required when designing and manufacturing seaweed surrogates to successfully replicate hydrodynamic performance of live organisms. Work in this direction was pioneered by Rominger and Nepf (2014) and Fryer et al. (2015) for examining the effects of longitudinal corrugations on the drag force and mass transfer in the surrogates of seaweed blades and should be applied more widely. This issue may appear of relatively low importance for bending plants (sensu Nikora, 2010) for which the contribution of the friction drag is much lower than that of the pressure drag. Nevertheless, as demonstrated by Aberle and Järvelä (2013), even riparian vegetation, which presents notorious examples of bending plants, cannot be replicated appropriately if leaves are not taken into account. Furthermore, the drag force exerted by the flow on leaves is dependent upon their morphological characteristics and mechanical properties as concluded by Albayrak et al. (2012). In particular Albayrak et al. (2012) found that an elliptic shape (similar to the shape of live seaweed blades used in the present study) is associated with higher $C_{d}$ than that for a rectangular shape (more similar to the shape of our surrogates) for low values of flexural rigidity. Moreover, the presence of roughness elements, such as bullations on seaweed blades, causes an increase in $C_{d}$ for a leaf/blade. It follows that an accurate and detailed description of morphological characteristics of leaves/blades is of primary importance for achieving an accurate characterisation of the drag force acting on vegetation.

To summarize, it is critical to apply a more rigorous approach to the design and manufacturing of vegetation surrogates. Even though in this study we have not examined seaweed blade morphology in detail, our findings suggest that intra-species morphological variation may play an important role in determining the drag force experienced by an organism. Hence, organisms of the same species growing at different sites and with similar main dimensions (e.g. length, mean width, wetted surface area) may experience drag forces significantly different from each other depending on the environmental factors that have affected their growth. Regarding this matter, we would also like to stress two points: (i) the lack of information of vegetation morphology, particularly for freshwater aquatic species and riparian species, limits our ability to investigate flow-vegetation interactions comprehensively; and (ii) plant allometry (e.g. Niklas, 1994) may contain key tools to help us incorporating intra-species morphological variation in the study of flow-vegetation interactions. Finally, we note that it is currently unclear how vegetation morphological small-scale features affect the drag force at a canopy or reach scale (i.e. in the applications in which vegetation is considered as roughness element on the bed of an open channel). Exploratory research in this area is required for providing engineers with the knowledge and tools for developing mathematical and physical models that are appropriate replicas of field conditions. 


\section{Conclusions}

This paper presents a comparison of the hydrodynamic performance of live seaweed blades of the species $S$. latissima and their surrogates designed based on similarity considerations. The hydrodynamics of test samples were assessed using data collected in flume experiments featuring synchronized measurements of flow velocities upstream and downstream of test samples, their drag forces, and reconfiguration. Surrogates were found to successfully reproduce many aspects of live seaweed blade hydrodynamics and essentially the same controlling mechanisms were identified for live seaweed blades and surrogates. Nevertheless, surrogates did not replicate the performances of live seaweed blades in terms of the drag coefficient and were more selective than live seaweed blades about the range of turbulence structures (i.e. their length scales) influencing their hydrodynamics. The findings of this study indicate that a high degree of accuracy is required in the design of the plant surrogates for replicating the hydrodynamic performance of vegetation. Macro-features present on the surface of blades have a primary role in determining the drag force exerted on them. Therefore, these often-overlooked morphological features should not be neglected in the design of vegetation surrogates.

\section{Acknowledgements}

The authors gratefully acknowledge the assistance of Elisa Bozzolan, Euan Judd, Henry Lecallet, and Olivia McCabe in collecting data sets used in this publication. The authors also thank Stuart Cameron and Euan Judd for support in developing video analysis routines, David Attwood and Hamish Biggs for their assistance during seaweed collection and transportation to the University of Aberdeen, and technicians Roy Gillanders and Benjamin Stratton for meticulous technical support of the experiments. Very useful comments provided by two anonymous reviewers, Associate Editor and Editor helped to improve the final version of the paper.

\section{Funding}

The work described in this publication was undertaken during the Ph.D. study of Davide Vettori at the University of Aberdeen funded by a scholarship from the Northern Research Partnership, Scotland.

\section{Notation}

$\begin{array}{lll}A_{\text {wet }} & = & \text { wetted surface area }\left(\mathrm{mm}^{2}\right) \\ b & = & (\text { mean}) \text { width of test sample }(\mathrm{mm}) \\ b_{\max } & = & \text { maximum width of test sample }(\mathrm{mm})\end{array}$




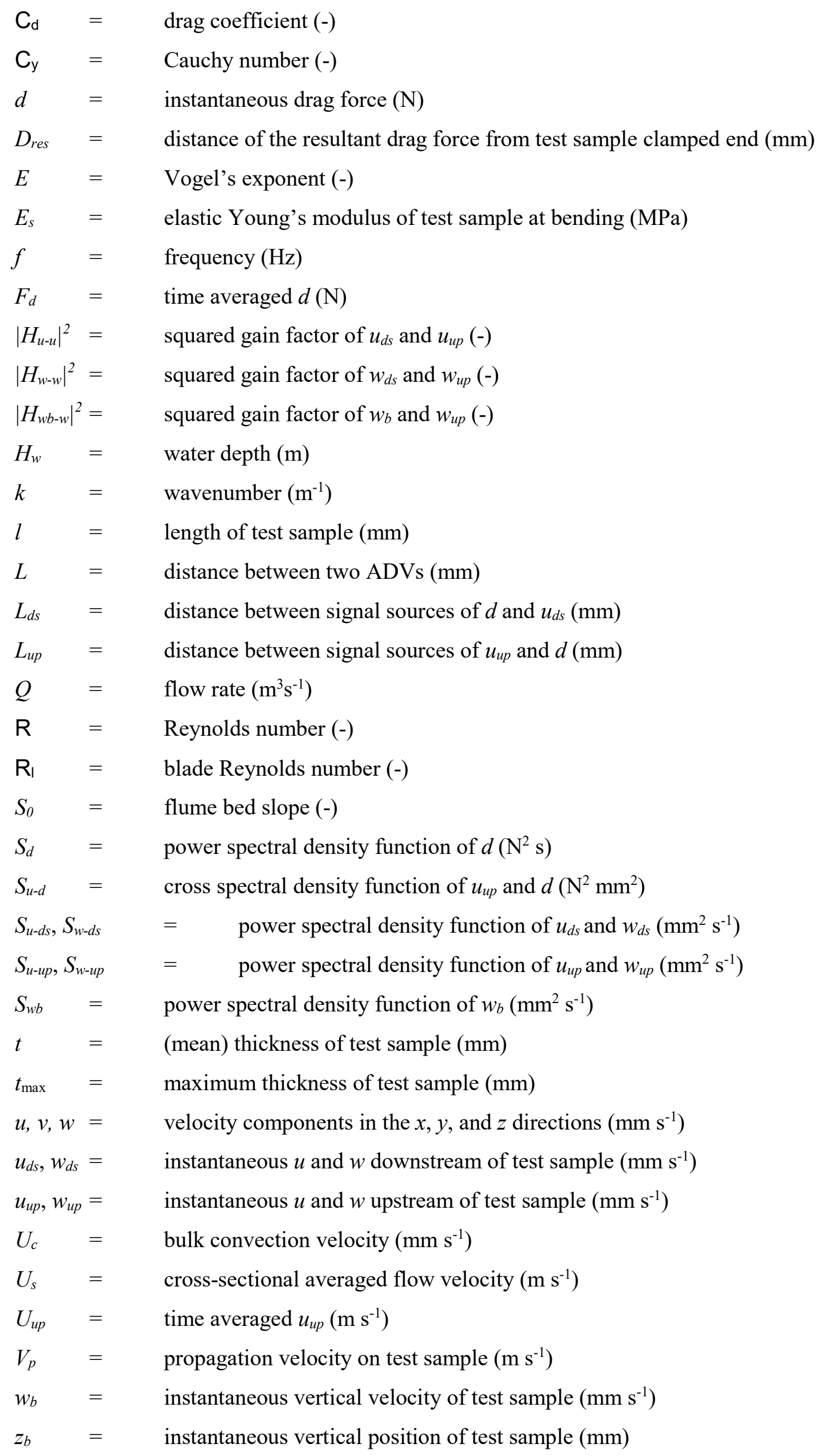




$$
\begin{array}{lll}
\gamma_{u-d}^{2} & = & \text { coherence function between } u_{u p} \text { and } d(-) \\
\Delta \tau & = & \text { time delay between two signals (s) } \\
v & = & \text { water kinematic viscosity }\left(\mathrm{m}^{2} \mathrm{~s}^{-1}\right) \\
\rho & = & \text { mass density of water }\left(\mathrm{kg} \mathrm{m}^{-3}\right) \\
\rho_{s} & = & \text { mass density of test sample }\left(\mathrm{kg} \mathrm{m}^{-3}\right) \\
\sigma_{d}^{2} & = & \text { variance of } d\left(\mathrm{~N}^{2}\right) \\
\sigma_{w b}^{2} & = & \text { variance of } w_{b}\left(\mathrm{~mm}^{2} \mathrm{~s}^{-2}\right) \\
\sigma_{z b} & = & \text { standard deviation of } z_{b}(\mathrm{~mm})
\end{array}
$$

\section{References}

Aberle, J., \& Järvelä, J. (2013). Flow resistance of emergent rigid and flexible floodplain vegetation. Journal of Hydraulic Research, 51(1), 33-45.

Albayrak, I., Nikora, V., Miler, O., \& O’Hare, M. (2012). Flow-plant interactions at a leaf scale: effects of leaf shape, serration, roughness and flexural rigidity. Aquatic Sciences, 74(2), 267-286.

Boller, M. L., \& Carrington, E. (2007). Interspecific comparison of hydrodynamic performance and structural properties among intertidal macroalgae. Journal of Experimental Biology, 210(11), 1874-1884.

Boothroyd, R. J., Hardy, R. J., Warburton, J., \& Marjoribanks, T. I. (2016). The importance of accurately representing submerged vegetation morphology in the numerical prediction of complex river flow. Earth Surface Processes and Landforms, 41(4), 567-576.

Buck, B. H., \& Buchholz, C. M. (2005). Response of offshore cultivated Laminaria saccharina to hydrodynamic forcing in the North Sea. Aquaculture, 250(3), 674-691.

de Langre, E. (2008). Effects of wind on plants. Annual Review of Fluid Mechanics, 40, 141168.

Canny, J. (1986). A computational approach to edge detection. IEEE Transactions on pattern analysis and machine intelligence, 6, 679-698.

Folkard, A. M. (2005). Hydrodynamics of model Posidonia oceanica patches in shallow water. Limnology and Oceanography, 50(5), 1592-1600.

Frostick, L. E., McLelland, S. J., \& Mercer, T. G. (2011). Users guide to physical modelling and experimentation: experience of the HYDRALAB network. Boca Raton, FL: CRC Press/Balkema.

Fryer, M., Terwagne, D., Reis, P. M., \& Nepf, H. (2015). Fabrication of flexible blade models from a silicone-based polymer to test the effect of surface corrugations on drag and blade motion. Limnology and Oceanography: Methods, 13(11), 630-639.

Ghisalberti, M., \& Nepf, H. (2005). Mass transport in vegetated shear flows. Environmental Fluid Mechanics, 5(6), 527-551. 
Goring, D. G., \& Nikora, V. I. (2002). Despiking acoustic Doppler velocimeter data. Journal of Hydraulic Engineering, 128(1), 117-126.

Johnson, A.S. (2001). Drag, drafting, and mechanical interactions in canopies of the red alga Chondrus crispus. The Biological Bulletin, 201(2), 126-135.

Kouwen, N., Unny, T. E., \& Hill, H. M. (1969). Flow retardance in vegetated channels. Journal of the Irrigation and Drainage Division, 95(2), 329-344.

Kouwen, N., \& Unny, T. E. (1973). Flexible roughness in open channels. Journal of the Hydraulics Division, 99(HY5), 713-727.

Lightbody, A. F., \& Nepf, H. M. (2006). Prediction of near-field shear dispersion in an emergent canopy with heterogeneous morphology. Environmental Fluid Mechanics, 6(5), 477-488.

Lucas, J. S., \& Southgate, P. C. (2012). Aquaculture: farming aquatic animals and plants. Hoboken, NJ: Wiley-Blackwell.

Naudascher, E., \& Rockwell, D. (2005). Flow-induced Vibrations: An Engineering Guide. Mineola, NY: Dover Publications, Inc.

Nepf, H. M. (2012). Hydrodynamics of vegetated channels. Journal of Hydraulic Research, $50(3), 262-279$.

Nezu, I., \& Sanjou, M. (2008). Turbulence structure and coherent motion in vegetated canopy open-channel flows. Journal of Hydro-environment Research, 2(2), 62-90.

Niklas, K. J. (1994). Plant allometry: the scaling of form and process. Chicago, IL: University of Chicago Press.

Nikora, N., Nikora, V., \& O'Donoghue, T. (2013). Velocity profiles in vegetated open-channel flows: combined effects of multiple mechanisms. Journal of Hydraulic Engineering, 139(10), 1021-1032.

Nikora, V. (2010). Hydrodynamics of aquatic ecosystems: an interface between ecology, biomechanics and environmental fluid mechanics. River Research and Applications 26(4), 367-384.

Okamoto, T., Nezu, I., \& Sanjou, M. (2016). Flow-vegetation interactions: length-scale of the “monami" phenomenon. Journal of Hydraulic Research, 54(3), 251-262.

Parsheh, M., Sotiropoulos, F., \& Porte'-Agel, F. (2010). Estimation of power spectra of acoustic-Doppler velocimetry data contaminated with intermittent spikes. Journal of Hydraulic Engineering, 136(6), 368-378.

Rominger, J. T., \& Nepf, H. M. (2014). Effects of blade flexural rigidity on drag force and mass transfer rates in model blades. Limnology and Oceanograph, 59(6), 2028-2041.

Schlichting, C. D. (1986). The evolution of phenotypic plasticity in plants. Annual Review of Ecology and Systematics, 17(1), 667-693.

Shumway, R. H., \& Stoffer, D. S. (2000). Time series analysis and its applications. Berlin: Springer. 
Siniscalchi, F., \& Nikora, V. (2012). Flow-plant interactions in open-channel flows: a comparative analysis of five freshwater plant species. Water Resources Research, 48(5), W05503.

Siniscalchi, F., Nikora, V. I., \& Aberle, J. (2012). Plant patch hydrodynamics in streams: Mean flow, turbulence, and drag forces. Water Resources Research, 48(1), W01513.

Siniscalchi, F., \& Nikora, V. (2013). Dynamic reconfiguration of aquatic plants and its interrelations with upstream turbulence and drag forces. Journal of Hydraulic Research, 51(1), 46-55.

Spurkland, T., \& Iken, K. (2012). Seasonal growth patterns of Saccharina latissima (Phaeophyceae, Ochrophyta) in a glacially-influenced subarctic estuary. Phycological Research, 60(4), 261-275.

Stewart, H.L. (2006). Hydrodynamic consequences of flexural stiffness and buoyancy for seaweeds: a study using physical models. Journal of Experimental Biology, 209(11), 21702181 .

Thomas, R. E., Johnson, M. F., Frostick, L. E., Parsons, D. R., Bouma, T. J., Dijkstra, J. T., ... McLelland, S. J. (2014). Physical modelling of water, fauna and flora: knowledge gaps, avenues for future research and infrastructural needs. Journal of Hydraulic Research, 52(3), 311-325.

Vettori, D. (2016). Hydrodynamic performance of seaweed farms: an experimental study at seaweed blade scale (Doctoral dissertation). Retrieved from https://www.abdn.ac.uk/library/collections/

Vettori, D., \& Nikora, V. (2017). Morphological and mechanical properties of blades of Saccharina latissima. Estuarine, Coastal and Shelf Science, 196, 1-9.

Vettori, D., \& Nikora, V. (2018). Flow-seaweed interactions: a laboratory study using blade models. Environmental Fluid Mechanics, 18(3), 611-636.

Vogel, S. (1994). Life in moving fluids: the physical biology of flow. Princeton, NJ: Princeton University Press.

Wilson, C. A. M. E., Stoesser, T., Bates, P. D., \& Pinzen, A. B. (2003). Open channel flow through different forms of submerged flexible vegetation. Journal of Hydraulic Engineering, 129(11), 847-853.

Yang, W., \& Choi, S. U. (2009). Impact of stem flexibility on mean flow and turbulence structure in depth-limited open channel flows with submerged vegetation. Journal of Hydraulic Research, 47(4), 445-454. 


\section{List of tables}

Table 1 Summary of morphological and mechanical characteristics of seaweed blades and their surrogates. Seaweed blades are ordered by length group and flow scenario, surrogates are ordered by length. Note that values of mass density $\rho_{s}$ and bending Young's modulus $E_{s}$ of seaweed blades are mean values obtained from measurements of about 80 blades (Vettori \& Nikora, 2017). Also note that the maximum and mean values of width $\left(b, b_{\max }\right)$ and thickness $(t$, $\left.t_{\max }\right)$ of surrogates are identical because surrogates were designed with a uniform width and thickness

Table 2 Hydraulic conditions of experiments 


\section{List of figures}

Figure 1 A live seaweed blade (background) and a seaweed blade surrogate (black contour). The surrogate is shown at the scale 1:1. Comparison of wetted surface area $A_{\text {wet }}$ of seaweed blades and their surrogates, values of surrogates at the scales 1:5 and 1:1 are reported (inset)

Figure 2 Side view of the experimental setup for assessing the hydrodynamic performance of test samples including parameters used in the estimation of the location of the resultant drag force

Figure 3 Drag coefficient $C_{d}$ of test samples as a function of: (a) the blade Reynolds number $R_{l}$ and (b) the Cauchy number $\mathrm{C}_{\mathrm{y}}$. Data for all flow scenarios and samples are shown

Figure 4 (a) Spectra $S_{d}$ of the drag force experienced by test samples, normalized by drag variance $\sigma_{d .}^{2}$. (b) Coherence function $\gamma_{u-d}^{2}$ between $u_{u p}$ and $d$ as a function of the ratio of sample length $l$ to eddy wavelength $f / U_{u p}$, where the thick horizontal line represents $1 \%$ significance level of the coherence function computed according to Shumway and Stoffer (2000). Data for all flow scenarios and samples are shown

Figure 5 (a) Time series of sample's free end vertical velocity $w_{b}$, cases shown are Group 2 Run 7 and L7 Run 7, Table. (b) Spectra $S_{w b}$ of the vertical velocity of test samples normalized by vertical velocity variance $\sigma_{w b}^{2}$ as a function of the ratio of sample length $l$ to eddy wavelength $f / U_{u p}$. (c) Squared gain factor $\left|H_{w b-w}\right|^{2}$ of the flow vertical velocity upstream of the test sample and sample's free end vertical velocity as a function of the ratio of sample length $l$ to the eddy wavelength $f / U_{u p}$. Data for all flow scenarios and samples are shown in (b) and (c)

Figure 6 Effects of test samples on flow characteristics assessed using squared gain factors $|H|^{2}$ of flow velocity components $u(\mathrm{a}-\mathrm{b})$ and $w(\mathrm{c}-\mathrm{d})$ upstream and downstream of the test samples: (a, c) squared gain factor is shown as a function of the ratio of sample length $l$ to the eddy wavelength $f / U_{u p}$; and (b, d) squared gain factor is shown as a function of the wavenumber $k$. Data for all flow scenarios and samples are shown

Figure 7 (a) Estimates of the propagation velocity $V_{p}$ normalized by the mean approach velocity $U_{u p}$ in front of a test sample as a function of the blade Reynolds number $\mathrm{R}_{\mathrm{l}}$. (b) Distance $D_{\text {res }}$ of the location of the resultant drag force from the sample clamped end normalized by the sample length $l$ as a function of the mean approach velocity $U_{u p}$ in front of a test sample. Data for all flow scenarios and samples are shown 
Table 1 Summary of morphological and mechanical characteristics of seaweed blades and their surrogates. Seaweed blades are ordered by length group and flow scenario, surrogates are ordered by length. Note that values of mass density $\rho_{s}$ and bending Young's modulus $E_{s}$ of seaweed blades are mean values obtained from measurements of about 80 blades (Vettori \& Nikora, 2017). Also note that the maximum and mean values of width $(b, b \max )$ and thickness $(t$, $\left.t_{\max }\right)$ of surrogates are identical because surrogates were designed with a uniform width and thickness

\begin{tabular}{|c|c|c|c|c|c|c|c|c|}
\hline & $\begin{array}{l}l \\
(\mathrm{~mm})\end{array}$ & $\begin{array}{l}b \\
(\mathrm{~mm})\end{array}$ & $\begin{array}{l}b_{\max } \\
(\mathrm{mm})\end{array}$ & $\begin{array}{l}t \\
(\mathrm{~mm})\end{array}$ & $\begin{array}{l}t_{\max } \\
(\mathrm{mm})\end{array}$ & $\begin{array}{l}A_{\text {wet }} \\
\left(\mathrm{mm}^{2}\right)\end{array}$ & $\begin{array}{l}\rho_{s} \\
\left(\mathrm{~kg} \mathrm{~m}^{-3}\right)\end{array}$ & $\begin{array}{l}E_{s} \\
(\mathrm{MPa})\end{array}$ \\
\hline \multicolumn{9}{|c|}{ Seaweeds } \\
\hline \multirow{3}{*}{ Group 1} & 196 & 38 & 62 & 0.18 & 0.43 & $1.4 \times 10^{4}$ & 1092 & 3.73 \\
\hline & 160 & 34 & 63 & 0.16 & 0.47 & $1.2 \times 10^{4}$ & 1092 & 3.73 \\
\hline & 205 & 36 & 68 & 0.23 & 0.42 & $1.6 \times 10^{4}$ & 1092 & 3.73 \\
\hline \multirow{3}{*}{ Group 2} & 275 & 36 & 77 & 0.17 & 0.65 & $2.6 \times 10^{4}$ & 1092 & 3.73 \\
\hline & 285 & 39 & 82 & 0.20 & 0.52 & $2.8 \times 10^{4}$ & 1092 & 3.73 \\
\hline & 310 & 36 & 81 & 0.21 & 0.91 & $3.4 \times 10^{4}$ & 1092 & 3.73 \\
\hline \multirow{3}{*}{ Group 3} & 424 & 47 & 132 & 0.23 & 0.93 & $6.2 \times 10^{4}$ & 1092 & 3.73 \\
\hline & 444 & 41 & 134 & 0.26 & 0.70 & $6.2 \times 10^{4}$ & 1092 & 3.73 \\
\hline & 419 & 49 & 124 & 0.24 & 0.76 & $5.4 \times 10^{4}$ & 1092 & 3.73 \\
\hline \multirow{3}{*}{ Group 4} & 519 & 45 & 181 & 0.24 & 0.83 & $1.1 \times 10^{5}$ & 1092 & 3.73 \\
\hline & 548 & 54 & 174 & 0.41 & 0.82 & $1.1 \times 10^{5}$ & 1092 & 3.73 \\
\hline & 516 & 49 & 17 & 0.36 & 1.54 & $1.3 \times 10^{5}$ & 1092 & 3.73 \\
\hline \multirow{3}{*}{ Group 5} & 570 & 74 & 127 & 0.25 & 0.85 & $7.2 \times 10^{4}$ & 1092 & 3.73 \\
\hline & 599 & 76 & 143 & 0.29 & 1.82 & $9.8 \times 10^{4}$ & 1092 & 3.73 \\
\hline & 601 & 69 & 118 & 0.28 & 1.21 & $8.2 \times 10^{4}$ & 1092 & 3.73 \\
\hline \multicolumn{9}{|c|}{ Surrogates } \\
\hline L1 & 70 & 6 & 6 & 0.07 & 0.07 & $4.0 \times 10^{2}$ & 1059 & 240 \\
\hline L2 & 90 & 7 & 7 & 0.12 & 0.12 & $6.3 \times 10^{2}$ & 935 & 205 \\
\hline L3 & 100 & 8 & 8 & 0.10 & 0.10 & $7.6 \times 10^{2}$ & 819 & 319 \\
\hline
\end{tabular}




\begin{tabular}{llllllll} 
L4 & 120 & 9 & 9 & 0.12 & 0.12 & $1.1 \times 10^{3} 935$ & 205 \\
L5 & 190 & 10 & 10 & 0.12 & 0.12 & $2.0 \times 10^{3} 935$ & 205 \\
L6 & 210 & 11 & 11 & 0.21 & 0.21 & $2.5 \times 10^{3} 856$ & 78 \\
L7 & 280 & 15 & 15 & 0.28 & 0.28 & $4.1 \times 10^{3} 992$ & 209 \\
L8 & 290 & 15 & 15 & 0.12 & 0.12 & $4.3 \times 10^{3} 935$ & 205 \\
L9 & 390 & 26 & 26 & 0.12 & 0.12 & $1.0 \times 10^{4} 935$ & 205 \\
\hline
\end{tabular}


Table 2 Hydraulic conditions of experiments

\begin{tabular}{lllllll}
\hline $\begin{array}{l}\text { Flow } \\
\text { scenario }\end{array}$ & $S_{0}$ & $Q\left(\mathrm{~m}^{3} \mathrm{~s}^{-1}\right)$ & $H_{w}(\mathrm{~m})$ & $U_{u p}\left(\mathrm{~m} \mathrm{~s}^{-1}\right)$ & $U_{s}\left(\mathrm{~m} \mathrm{~s}^{-1}\right)$ & $\begin{array}{l}\mathrm{R}= \\
U_{u p} H_{w} / v\end{array}$ \\
\hline Run 1 & $1: 1000$ & $7.0 \times 10^{-3}$ & 0.3 & 0.10 & 0.09 & 27,000 \\
Run 2 & $1: 1000$ & $11.8 \times 10^{-3}$ & 0.3 & 0.18 & 0.16 & 48,000 \\
Run 3 & $1: 1000$ & $16.6 \times 10^{-3}$ & 0.3 & 0.26 & 0.22 & 66,000 \\
Run 4 & $1: 1000$ & $21.5 \times 10^{-3}$ & 0.3 & 0.33 & 0.29 & 87,000 \\
Run 5 & $1: 1000$ & $26.4 \times 10^{-3}$ & 0.3 & 0.40 & 0.35 & 105,000 \\
Run 6 & $1: 500$ & $31.2 \times 10^{-3}$ & 0.3 & 0.47 & 0.42 & 126,000 \\
Run 7 & $1: 500$ & $36.0 \times 10^{-3}$ & 0.3 & 0.55 & 0.48 & 144,000 \\
\hline
\end{tabular}




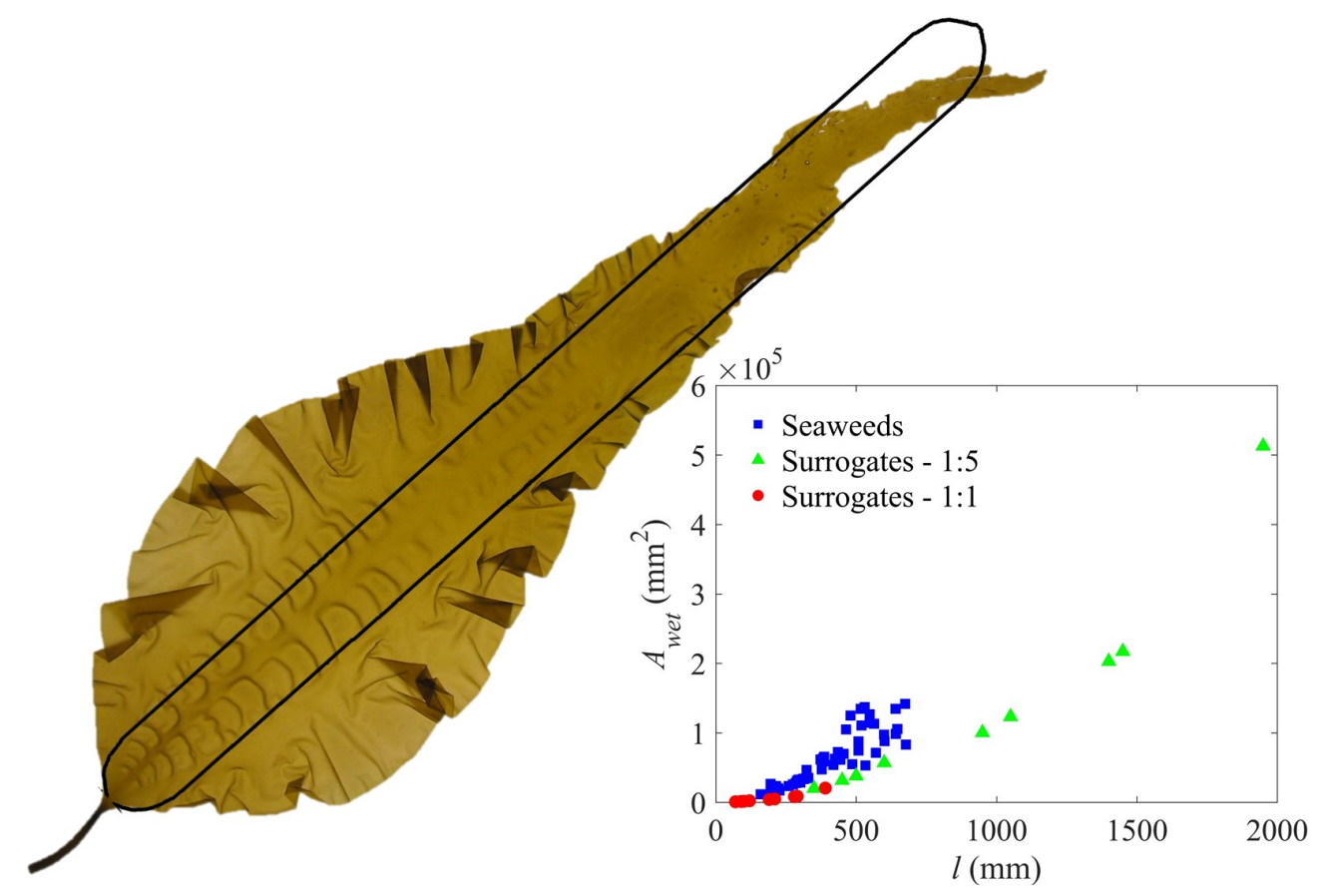

Figure 1 A live seaweed blade (background) and a seaweed blade surrogate (black contour). The surrogate is shown at the scale 1:1. Comparison of wetted surface area $A_{\text {wet }}$ of seaweed blades and their surrogates, values of surrogates at the scales 1:5 and 1:1 are reported (inset) 


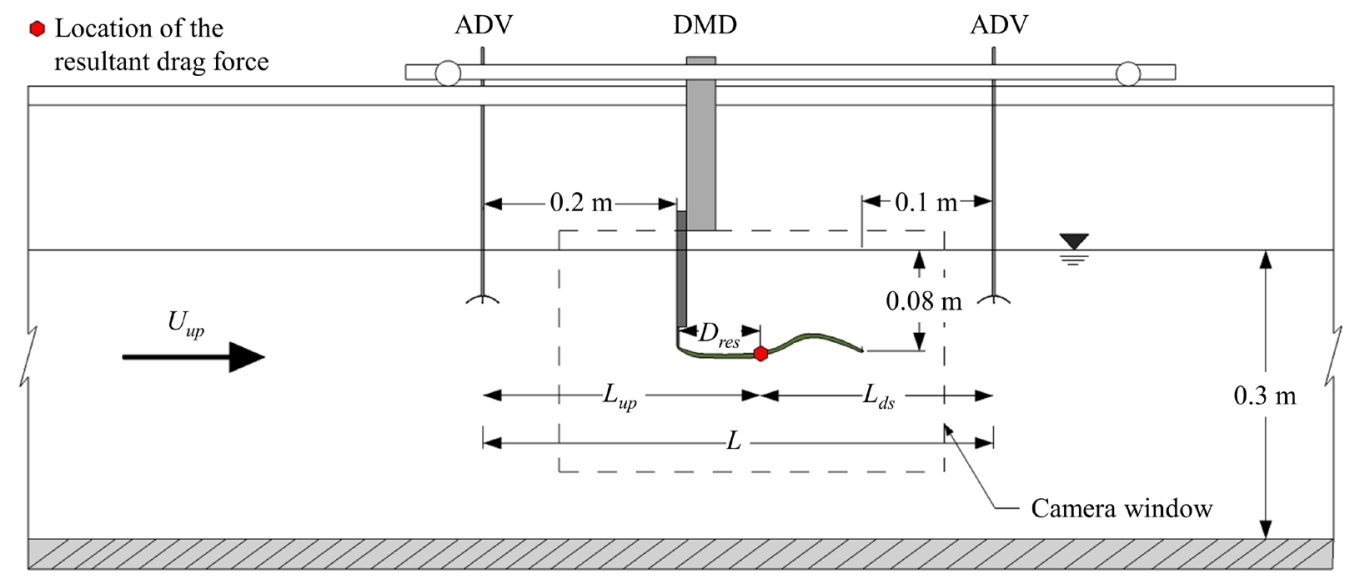

Figure 2 Side view of the experimental setup for assessing the hydrodynamic performance of test samples including parameters used in the estimation of the location of the resultant drag force 
(a)

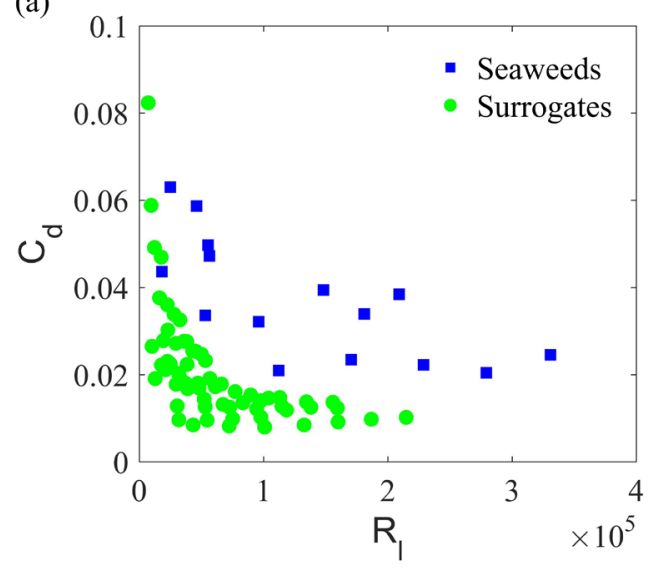

(b)

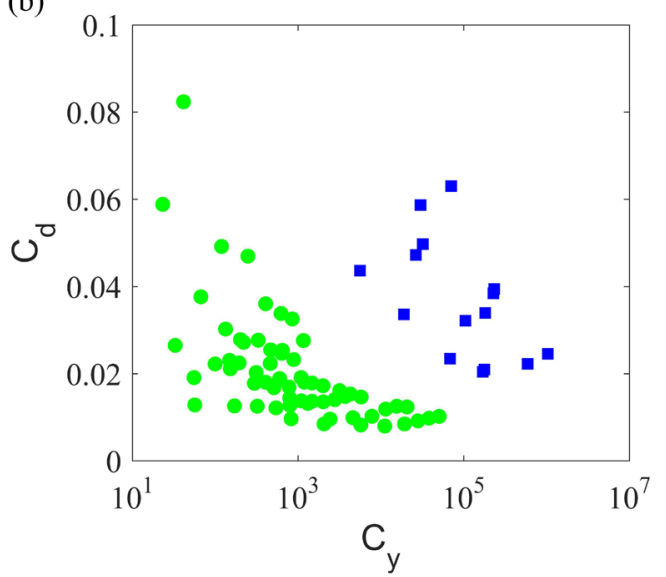

Figure 3 Drag coefficient $C_{d}$ of test samples as a function of: (a) the blade Reynolds number $R_{l}$ and (b) the Cauchy number $\mathrm{C}_{\mathrm{y}}$. Data for all flow scenarios and samples are shown 

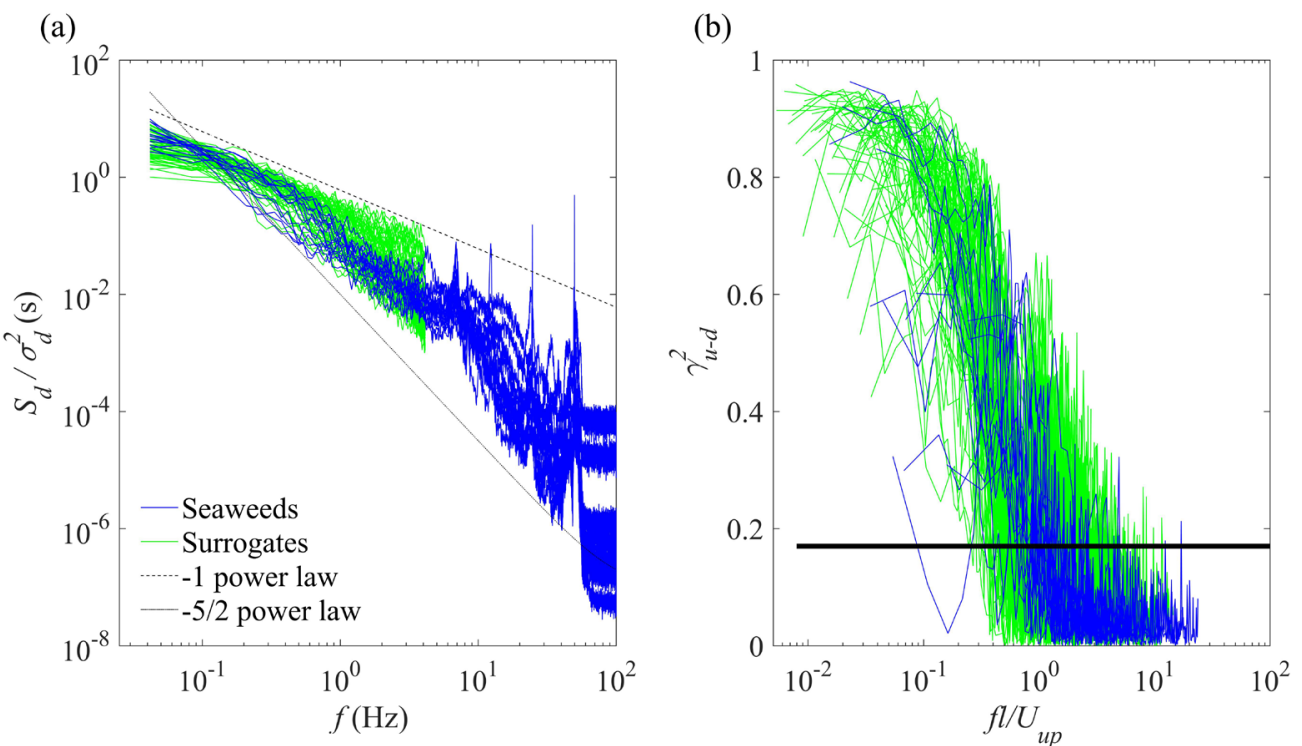

Figure 4 (a) Spectra $S_{d}$ of the drag force experienced by test samples, normalized by drag variance $\sigma_{d .}^{2}$. (b) Coherence function $\gamma_{u-d}^{2}$ between $u_{u p}$ and $d$ as a function of the ratio of sample length $l$ to eddy wavelength $f / U_{u p}$, where the thick horizontal line represents $1 \%$ significance level of the coherence function computed according to Shumway and Stoffer (2000). Data for all flow scenarios and samples are shown 

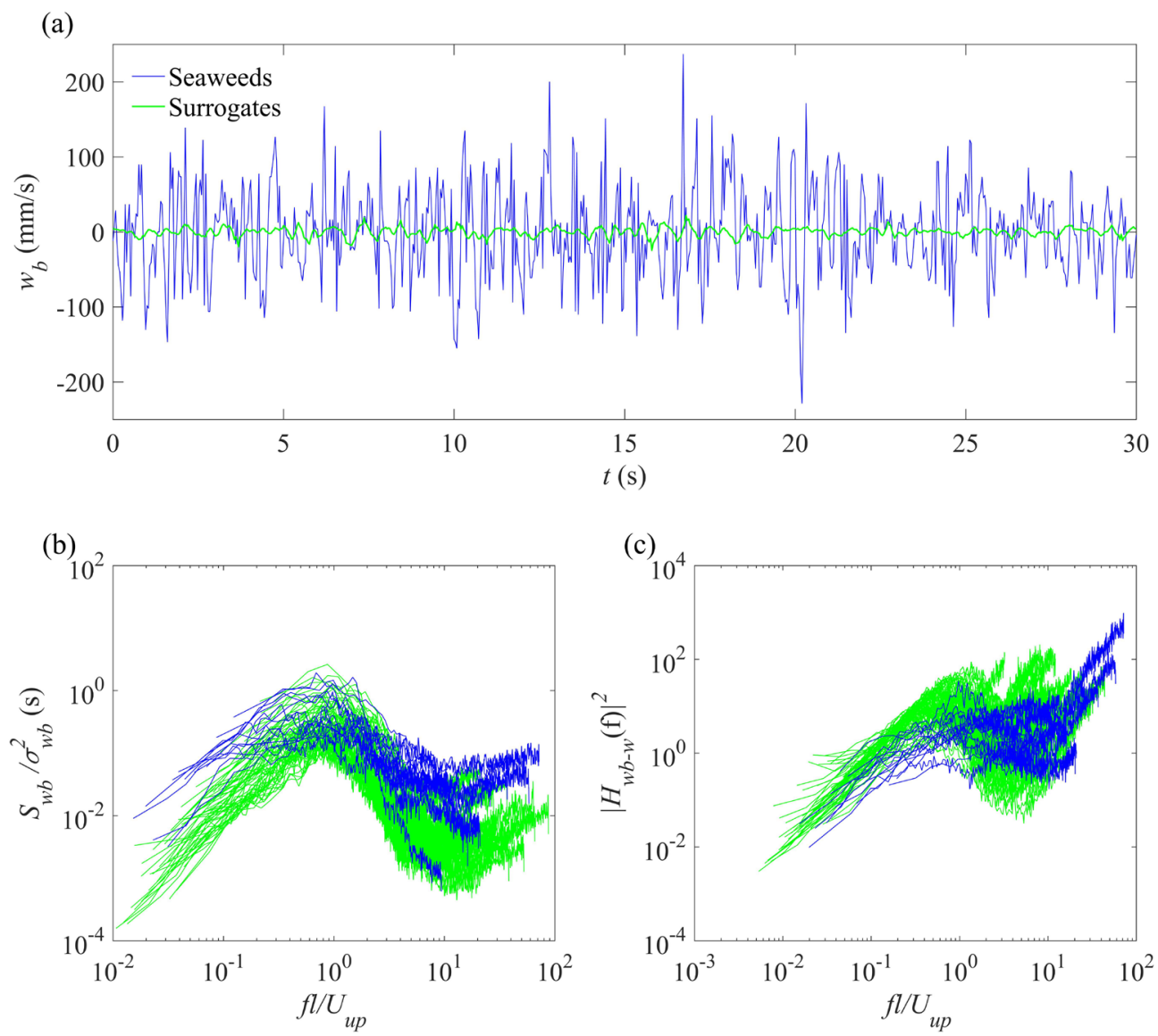

Figure 5 (a) Time series of sample's free end vertical velocity $w_{b}$, cases shown are Group 2 Run 7 and L7 Run 7, Table. (b) Spectra $S_{w b}$ of the vertical velocity of test samples normalized by vertical velocity variance $\sigma_{w b}^{2}$ as a function of the ratio of sample length $l$ to eddy wavelength $f / U_{u p}$. (c) Squared gain factor $\left|H_{w b-w}\right|^{2}$ of the flow vertical velocity upstream of the test sample and sample's free end vertical velocity as a function of the ratio of sample length $l$ to the eddy wavelength $f / U_{u p}$. Data for all flow scenarios and samples are shown in (b) and (c) 
(a)

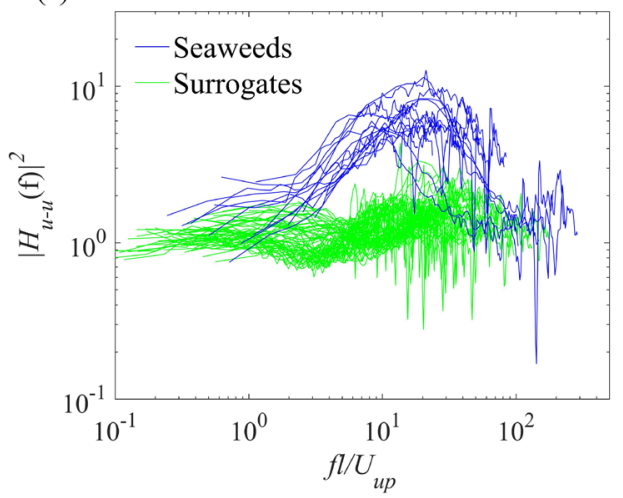

(c)

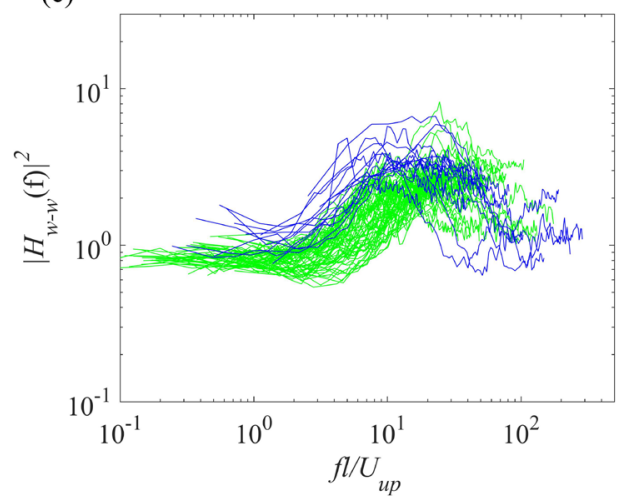

(b)

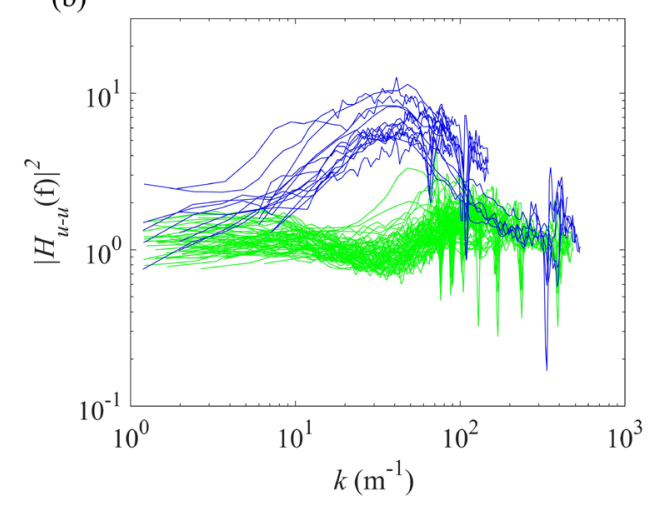

(d)

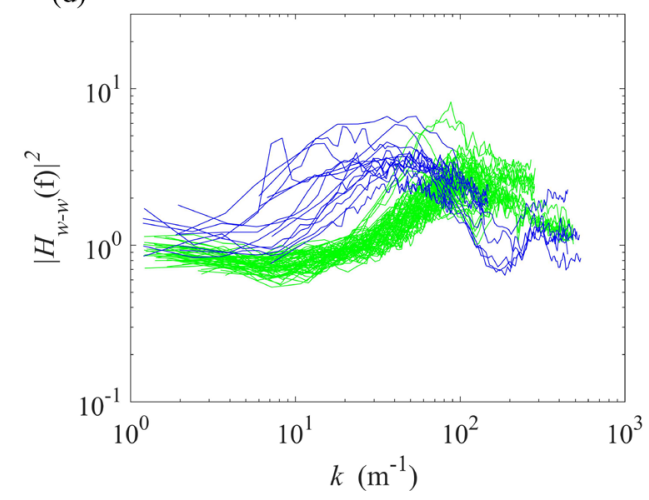

Figure 6 Effects of test samples on flow characteristics assessed using squared gain factors $|H|^{2}$ of flow velocity components $u(\mathrm{a}-\mathrm{b})$ and $w(\mathrm{c}-\mathrm{d})$ upstream and downstream of the test samples: $(a, c)$ squared gain factor is shown as a function of the ratio of sample length $l$ to the eddy wavelength $f / U_{u p}$; and (b, d) squared gain factor is shown as a function of the wavenumber $k$. Data for all flow scenarios and samples are shown 
(a)

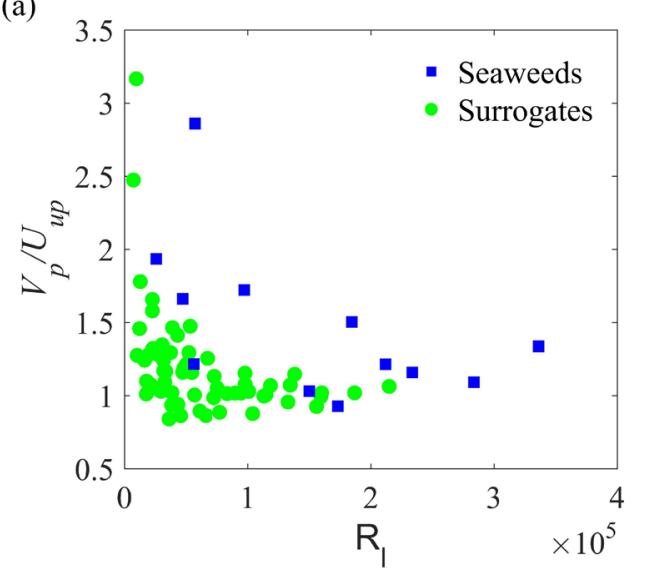

(b)

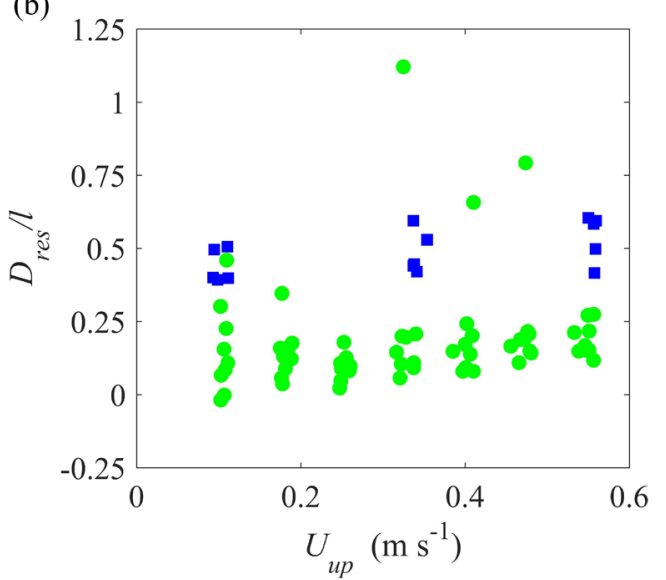

Figure 7 (a) Estimates of the propagation velocity $V_{p}$ normalized by the mean approach velocity $U_{u p}$ in front of a test sample as a function of the blade Reynolds number $\mathrm{R}_{\mathrm{I}}$. (b) Distance $D_{\text {res }}$ of the location of the resultant drag force from the sample clamped end normalized by the sample length $l$ as a function of the mean approach velocity $U_{u p}$ in front of a test sample. Data for all flow scenarios and samples are shown 